\title{
Article
}

\section{Prospective associations between loneliness and emotional intelligence}

\author{
Wols, A., Scholte, R.H.J. and Qualter, P. \\ Available at http://clok.uclan.ac.uk/11673/ \\ Wols, A., Scholte, R.H.J. and Qualter, P. (2015) Prospective associations \\ between loneliness and emotional intelligence. Journal of Adolescence, 39 . \\ pp. 40-48.
}

It is advisable to refer to the publisher's version if you intend to cite from the work. http://dx.doi.org/10.1016/j.adolescence.2014.12.007

For more information about UCLan's research in this area go to http://www.uclan.ac.uk/researchgroups/ and search for < name of research Group>.

For information about Research generally at UCLan please go to http://www.uclan.ac.uk/research/

All outputs in CLoK are protected by Intellectual Property Rights law, including Copyright law. Copyright, IPR and Moral Rights for the works on this site are retained by the individual authors and/or other copyright owners. Terms and conditions for use of this material are defined in the policies page.

\section{CLoK}

Central Lancashire online Knowledge www.clok.uclan.ac.uk

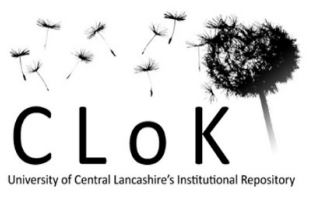


PROSPECTIVE ASSOCIATIONS BETWEEN LONELINESS AND EMOTIONAL INTELLIGENCE
A. Wols ${ }^{1}$, R.H.J. Scholte ${ }^{1}$, and P. Qualter ${ }^{2 *}$.

1. Behavioural Science Institute, Radboud University Nijmegen, Nijmegen, The Netherlands.

2. School of Psychology, University of Central Lancashire, Preston, Lancashire, UK.

*Correspondence contact: Pamela Qualter, School of Psychology, University of Central Lancashire, Preston, Lancashire, UK, PR1 2HE: Email: PQualter@uclan.ac.uk

Other: Wols, A., Scholte, R.H.J., \& Qualter, P. (2015). Prospective associations between loneliness and emotional intelligence. Journal of Adolescence, 39, 40-48. Available at: http://www.sciencedirect.com/science/article/pii/S0140197114002127

PLEASE NOTE: In the journal's version of the paper, there is a mistake in Table 1 and another in Figure 1b. In Table 1, the correlation between T1 Strategic AEI and T2 Strategic AEI for males was noted as -.216 and it should read .216; the correct interpretation is provided in the publisher's version of the paper, with reference to a positive association between Strategic AEI at T1 and T2. In Figure 1b, the incorrect beta is given for the T2 association between loneliness and Experiential AEI. The 
RUNNING HEAD: LONELINESS AND EMOTIONAL INTELLIGENCE

correct value is -.179 and not -.229 . Corrections to the publisher's version of the paper are provided here following guidance from the handling editor who was of the opinion that an official corrigendum was not necessary. That handling editor felt that these mistakes were minor and, therefore, correcting them would not alter the substantive interpretation provided in the paper. 


\begin{abstract}
Loneliness has been linked cross-sectionally to emotional skill deficits (e.g., Zysberg, 2012), but missing from the literature is a longitudinal examination of these relationships. The present study fills that gap by examining the prospective relationships between loneliness and emotional functioning in young adolescents in England. One hundred and ninety-six adolescents aged 11-13 years (90 females) took part in the study and completed the youth version of the Mayer-Salovey-Caruso Emotional Intelligence Test (MSCEIT-YV) and the peer-related subscale of the Loneliness and Aloneness Scale for Children and Adolescents (LACA) at two time points, which were 10 months apart. Prospective associations were obtained for male and female adolescents separately using cross-lagged statistical techniques. Our results showed prospective links between understanding and managing emotions and loneliness for both females and males. Perceiving and using emotions were prospectively linked to loneliness in males only. Possible explanations and directions for future research are discussed.
\end{abstract}

Key words: Loneliness, Emotional Intelligence, Youth, Adolescence, Emotion Regulation. 


\section{Introduction}

Loneliness is characterized across development as the perceived dissatisfaction with current social relationships (De Jong-Gierveld, 1987; Perlman \& Peplau, 1981) and is marked by negative feelings, including sadness and pessimism (Cacioppo \& Hawkley, 2005). It often develops under social circumstances where social connection needs are not met, including the ending of a relationship (Peplau \& Perlman, 1979), the move to a new city or school (Perlman \& Peplau, 1981), or during life transitions more generally (Young, 1982). The aversive feelings activated when lonely motivate us to reengage with others, which means loneliness is typically transient (Cacioppo \& Hawkley, 2009). However, a number of recent multi-wave longitudinal studies that investigated developmental trajectories of loneliness from childhood through adolescence and into early adulthood showed that some people experience high stable or increasing levels of loneliness over several years (Jobe-Schields, Cohen, \& Parra, 2011; Ladd \& Ettekal, 2013; Qualter, Brown et al., 2013; Schinka, Van Dulmen, Mata, Bossarte, \& Swahn, 2013; Vanhalst, Klimstra et al., 2012; Vanhalst, Rassart et al., 2013).

Prolonged loneliness is related to a host of psychological and physical health problems in adulthood (for reviews, see Hawkley \& Cacioppo, 2010; Heinrich \& Gullone, 2006), but the health implications of prolonged loneliness are also evident during adolescence. For example, chronic loneliness during adolescence predicts poor physical health (Harris, Qualter, \& Robinson, 2013; Qualter, Brown, et al., 2013) and increases in anxiety and depressive symptoms (Qualter, Brown, Munn, \& Rotenberg, 2010; Qualter, Brown et al., 2013; Schinka, Van Dulmen, Bossarte, \& Swahn, 2012; Schinka et al., 2013; Vanhalst, Goossens, Luycks, Scholte, \& Engels, 2013), with those 
highest on loneliness showing the biggest gains in depressive symptoms over time (Ladd \& Ettekal, 2013). There is also an association between suicidal ideation and loneliness during childhood and adolescence (Schinka et al., 2012, 2013).

Given the negative health outcomes of prolonged loneliness during adolescence, researchers have examined interpersonal factors that predict risk of prolonged loneliness. Findings show that low self-worth and personality traits (i.e., introversion and emotional instability) predict prolonged loneliness across childhood and adolescence (Qualter, Brown et al., 2013; Vanhalst, Goossens et al., 2013). Recent empirical prospective work also suggests that poor emotion regulation skills predict increases in loneliness over time (Nightingale et al., 2013; Vanhalst, Luyckx, Raes, \& Goossens, 2012).

In the current study, we extend previous work that has established a link between poor emotion regulation and later loneliness to look at emotional skills more generally. We build on the arguments posited by Heinrich and Gullone (2006, p. 712) that prospective work examining emotional skills and emotion regulation "may provide a promising avenue for future loneliness research”, especially among adolescents. The current study was designed to examine the prospective association between emotional skills and loneliness in a sample of early adolescents.

\section{Loneliness and Emotional Skills}

In the present study we consider emotional skills in the context of the framework of ability emotional intelligence (AEI), which includes four different emotional abilities: perceiving emotions, using emotions to facilitate thought, understanding emotions, and managing emotions (Mayer, Salovey, Caruso, 2008; Rivers, Brackett, Salovey, 2008). Ability emotional intelligence can be seen as an 
intelligence which addresses "the capacity to reason with and about emotions and/or (...) the contribution of the emotions system to enhancing intelligence" (Mayer et al., 2008, p. 505); emotions and emotion-relevant stimuli are used to guide thinking and behavior.

AEI has been linked to loneliness, life-satisfaction, relationship quality, academic success, and social competence in previous research with adolescent samples (Ciarrochi, Chan, \& Caputi, 2000; Lopes, Salovey, \& Straus, 2003; Lopes et al., 2004; Márquez, Martín, \& Brackett, 2006; Mestre, Guil, Lopes, Salovey, \& Gil-Olarte, 2006; Zysberg, 2012). In some of those studies specific aspects of AEI were associated with specific social outcomes: Emotion regulation was related to reported satisfaction with social support from others (Ciarrochi et al., 2000), self-reported social support from parents (Lopes et al., 2003), quality of interaction with friends (Lopes et al., 2014), quality of interaction with people of the opposite sex (Lopes et al., 2014), and teacher ratings of negative interactions with peers (Mestre, et al., 2006); Emotion perception was associated with the amount of, and satisfaction with, social support (Ciarrochi et al., 2000), and loneliness (Zysberg, 2012). In the Lopes et al. (2004) and Márquez et al., (2006) studies, all aspects of AEI were negatively associated with self-reported negative interaction with close friends and a host of self-reported social strategies. These studies suggest that different aspects of emotional skills are related to loneliness and social constructs associated with loneliness, but these relationships have only been examined cross-sectionally. Prospective examination of how different dimensions of AEI skills predicts changes in loneliness is warranted.

Why Are Emotional Skills Important in Understanding Loneliness? 
From an evolutionary perspective, loneliness is viewed as an adaptive process because negative emotions we feel when we are socially disconnected motivate us to repair connections and strengthen social relations (Cacioppo et al., 2006; Cacioppo \& Hawkley, 2009). Based on this model, successfully overcoming loneliness requires people to perceive and manage the negative feelings associated with loneliness effectively (Cacioppo \& Patrick, 2008). Recent prospective work supports this idea and shows that poor emotion regulation skills predict increases in loneliness over time (Nightingale et al., 2013; Vanhalst, Luyckx et al., 2012). However, there is currently no published work examining the role of emotion perception skills in predicting changes in loneliness over time. We would expect that people who are unable to identify their own emotions would have problems understanding that they feel a certain way because they are lonely, and these problems in emotional identification will reduce the likelihood of reconnection with other people.

Other AEI dimensions may also be important for predicting changes in loneliness. Where someone does not understand the complicated relationship between emotions, including how they evolve over time (understanding emotion), they may not understand that the negative feelings they are experiencing - be it sadness, pessimism, hostility, or irritability - are all triggered by loneliness. Because a person does not understand this common origin of their negative feelings, they may not be in a position to reconnect with others and reduce loneliness over time.

So far, we have talked about how AEI might impact response to loneliness, but there is also the question of whether feeling loneliness impacts emotional skills, particularly emotion regulation, over time. The evolutionary model of loneliness posits that perceived social disconnection is tantamount to feeling unsafe, and this sets off 
implicit hypervigilance for social threat in the environment (Cacioppo \& Hawkley, 2009). One of the consequences of this mechanism is a diminished capacity for emotion regulation (Hawkley \& Cacioppo, 2010). Evidence to support this notion comes from empirical work showing that loneliness increases our attention to certain sources of information at the expense of other important information (Bangee, Harris, Bridges, Rotenberg, \& Qualter, 2014; Cacioppo et al., 2000; Qualter, Rotenberg et al., 2013). That work suggests that effortful attentional processes, including emotion regulation, are compromised by heightened feelings of loneliness. We extend that work to examine these relationships over time.

Based on the evidence detailed above, in the current prospective study we examine the reciprocal relationships between loneliness and different dimensions of AEI. We expected to find that aspects of AEI predict changes in loneliness, but also that feelings of loneliness impair the capacity to regulate emotions over time. Thus, we should find bi-directional prospective relationships between loneliness and emotional functioning. We chose to explore these relationships during the transition to high school (age 11-12 years) when most pupils experience a degree of anxiety (Wigfield, Eccles, MacIver, Reuman, \& Midgley, 1991) and loneliness in response to changing social roles (Pellegrini, 2002; Pellegrini \& Long, 2002). We think that examining prospective associations between AEI and loneliness among young adolescents in their first year of high school is important because during that year young adolescents will experience heightened levels of social change and anxiety about their place in the social group. Thus, in the current study, we examined loneliness and AEI at the start of the academic year (Time 1) and 10 months later as school finished for the summer (Time 2). We examined cross-sectional associations at Time 1 and Time 2, but also the across-time 
association between loneliness and AEI.

\section{The Importance of Gender}

We expected the relationship between loneliness and emotional functioning to be moderated by gender. Several lines of reasoning led us to this expectation. First, females tend to score higher on tests of emotional skills than males. This effect is found among children, adolescents, and adults (Brackett \& Mayer, 2003; Brackett, Mayer, \& Warner, 2004; Brackett, Rivers, Shiffman, Lerner, \& Salovey, 2006; Brackett, Warner, \& Bosco, 2005; Rivers et al., 2012). Second, females report higher levels of interpersonal vulnerability (e.g., fear of abandonment and desires for intense closeness) and are more concerned with the quality of their interpersonal relationships (Leadbeater, Blatt, \& Quinlan, 1995, in Leadbeater, Kuperminc, Blatt, \& Hertzog, 1999; Leadbeater et al., 1999). This sensitivity to interpersonal concerns among females may result in higher feelings of loneliness compared to males. Although empirical studies have found these gender differences, there is no empirical evidence of how these gender differences may influence the relationship between emotional functioning and loneliness. So, we adopted an exploratory approach with regard to gender differences in the prospective association between emotional functioning and loneliness.

\section{Study Aims}

Cross-sectional associations between loneliness and other social relationships constructs and emotional functioning have been reported. But, there are no prospective examinations of the relationships between loneliness and emotional functioning beyond the studies by Nightingale et al. (2013) and Vanhalst, Luyckx et al. (2012) that looked only at emotion regulation and rumination respectively. There are also no studies that include a young adolescent sample. In the current study, we used a prospective design 
to investigate (1) whether poor emotional skills in early adolescence puts youth at risk of increased loneliness, and (2) the degree to which loneliness has short-term prospective effects on emotional functioning, independent of any reciprocal effects of emotional functioning on loneliness. We used a test of AEI to measure emotional functioning and utilized cross-lagged statistical techniques, which allow for accurate estimates of cross-time effects that link loneliness and emotional functioning, with age as an appropriate control for within-time associations and stability coefficients. We applied a multiple-group model to examine whether the cross-time effects of loneliness and emotional functioning were different for male and female adolescents.

\section{Method}

\section{Participants}

One hundred and ninety-six young adolescents (90 females) took part in the current study. All participants were enrolled in the UK state education system and were primarily Caucasian. All participants were students at a school in the South-East of England that covered a large geographical area within its district. The Index of Multiple Deprivation (IMD 2010) was used as an indicator of SES (municipal rather than family level), with postcode (zip code) information suggesting that the school sits in a local authority that is similar to that of average local authorities in England (https://www.gov.uk/government/collections/english-indices-of-deprivation). The children were not living in areas of intense social deprivation, but they were also not living in excessively wealthy areas of England.

Participation in the study was secured by the school principal and by verbal assent of the participants on the day of data collection. An opt-out procedure was used with parents, where they were asked to contact the researchers or the school if they did 
not want their child to take part in the study. Child participants had the right to end their participation in the study at any time. All participants were tested in accordance with the national and local ethics guidelines. The participants were in their first year of high school and were aged 11 to 13 years $($ Mean $=11.73, S D=.67)$ at Time $1(\mathrm{~T} 1)$ of the study.

\section{Measures}

Loneliness. Loneliness was assessed using the peer-related subscale of the Loneliness and Aloneness Scale for Children and Adolescents (LACA: Marcoen, Goossens, \& Caes, 1987). This subscale comprises items where the adolescent is asked to rate on a four-point scale how much they felt in a particular way (e.g., 'I feel alone at school'). The total scores could range from 12 to 48 with higher scores indicating more peer-related loneliness. Internal consistency for the subscale was high in previous studies $(\alpha \geq .86)$. Reliability in the current study was $\alpha=.84$ and .89 for males at Times 1 and 2 (T1 and T2) respectively, and $\alpha=.82$ at $\mathrm{T} 1$ and .89 at $\mathrm{T} 2$ for females.

Emotional intelligence (EI). The youth version of the Mayer-Salovey-Caruso Emotional Intelligence Test (MSCEIT-YV: Mayer, Salovey, \& Caruso, 2005) was used to assess emotional functioning. The measure assesses how well adolescents perform emotional tasks and solve emotional problems. This test consists of 101 items (of which 97 are scored) and measures the ability-based EI for adolescents aged 11 to 17 years. The MSCEIT-YV provides scores of emotional functioning in four domains (perceiving, using, understanding, and managing emotions) but it also provides two Area scores (Experiential EI [perceiving + using] and Strategic EI [understanding + managing]), and a Total EI score (based on all four domains) (Mayer, Salovey, \& Caruso, 2002; Mayer et al., 2005; Rivers et al., 2008; Stough, Saklofske, \& Parker, 
2009). The actual scores can be interpreted as intelligence scores $($ Mean $=100, S D=$ 15) (Mayer et al., 2002; Rivers et al., 2008; Stough et al., 2009). It took participants between 23-51 minutes to complete this task.

The MSCEIT-YV includes four sections. In Section A (perceive), the adolescent identifies the emotions expressed by a series of faces (e.g., 'How much of each feeling below do you see in this face?'). Section B (use) includes a set of vignettes and tasks that assess whether the adolescent is able to link emotions to physical sensations / to use emotions to facilitate thinking (e.g., 'Imagine that you are feeling cold, slow, and heavy. How much is this feeling like each of these other feelings?'). In Section C (understand) the adolescent chooses the emotion a protagonist is feeling in a series of vignettes (e.g., 'When Elizabeth discovered that she had not been chosen for the team after all, she felt '). In Section D (manage) the adolescent chooses which strategies are most helpful in managing certain emotions presented in a set of vignettes (e.g., 'A boy received some very sad news. He wants to feel happy before going to a fun party. How helpful would each of the following be in getting the boy to feel happy? 1 . The boy watches a sad movie, 2 . The boy reads a good book, 3 . The boy plays a game with his best friend'). Internal consistency scores of the MSCEIT-YV are provided in the manual for the four domains, with split-half reliabilities ranging from $\alpha=.67$ (Section A: Perceiving emotions) to .86 (Section C: Understanding emotions); the overall measure $\alpha=.91$. Because the answers were scored by the test publishers (Multi-Health Systems (MHS); Toronto, Canada) using expert norms, no reliabilities with regard to the current sample are reported. However, previous research among young adolescents report that the MSCEIT-YV can reliably measure the four emotional abilities, and that the factor structure is in accord with the theoretical model (Rivers, et al., 2012). Split-half 
reliabilities with regard to the Area scores are moderate to acceptable, with $r \geq .88$ for the Experiential area, and $r \geq .62$ for the Strategic area (Rivers et al., 2008). Further, the MSCEIT-YV has been linked to academic, personal, and social functioning (Rivers, Brackett, \& Salovey, 2006, in Rivers et al., 2008). Because of sample size, Area scores are used in the current study to examine the prospective associations between Experiential EI, Strategic EI, and loneliness.

\section{Procedure}

Participants completed the loneliness and emotional intelligence assessments at the beginning and end of a new academic year. This meant data collection time points were 10 months apart (September of one year and July of the following year). The adolescents completed both assessments on-line.

Adolescents starting high school in England come from several primary schools. All adolescents in the study knew some peers in their new year-group from their previous primary school. They were now in a much bigger cohort and had the potential to meet many more peers who could be potential friends, but they also had to find their place within the new social group and figure out the new social rules (cf. Pellegrini, 2002).

\section{Overview of Analyses}

We used a cross-lagged panel model approach to address both cross-sectional and longitudinal influences on loneliness and emotional functioning. Based on correlational analyses, age was included as a control variable that was associated with emotional functioning at $\mathrm{T} 1$ and $\mathrm{T} 2$. We investigated (1) whether loneliness predicted emotional functioning over time, and (2) the degree to which emotional functioning predicted loneliness over time, independent of any reciprocal effects of loneliness on 
emotional functioning. Cross-lagged panel analysis is a practical analytic solution for answering these questions because it allows modeling of prospective effects of loneliness on emotional functioning, and vice versa.

Cross-lagged panel analyses with observed variables were performed in AMOS 21 (Arbuckle, 2012). All analyses were conducted using full information maximum likelihood estimation with robust standard errors (Little \& Rubin, 1987). We used multiple-group analyses so we could examine whether the magnitude of the effects were different for males and females. In Stage 1, we examined a baseline panel model, with within-time associations and stability coefficients. In Stage 2 of the model testing, we included the cross-lagged effects in the model. Within-time associations and stability coefficients remained in the model, which allowed an examination of the cross-lagged effects of loneliness and emotional functioning whilst controlling for the effects of within-time associations and stability of the constructs over time. The degree of model fit at each stage was used to make interpretations about the effects within and over time. There are rules of thumb about acceptable levels of goodness of fit (GoF: Marsh, Hau, $\&$ Wen, 2004), such that the root mean square error of approximation (RMSEA) should be less than .05 to be viewed as having a good fit, the comparative fit index (CFI) and normed fit index (NFI) should exceed .90, and the Chi-square index should be as small as possible, preferably non-significant. We report standardized regression coefficients $(B)$ and correlations ( $r$, obtained as standardized regression coefficients). The alpha level is set to .05 throughout for the cross-lagged analyses. We examined whether there was a change in the GoF indexes with the addition of the cross-lagged paths and we used multiple-groups analyses in AMOS 21 to allow an examination of the baseline and cross-lagged models for males and females separately. Following cross-lagged 
analyses, the Fisher's $r$ to $Z$ transformation statistic was used to test whether there were significant differences in the size of the effects across and within-time for loneliness, Experiential EI, and Strategic EI for males and females.

\section{Results}

\section{Preliminary Analyses}

Table 1 presents all correlations between loneliness and the two areas of EI (Experiential EI and Strategic EI) at the two time points. Findings show small to medium negative within-time and across-time correlations between loneliness and Strategic EI for females and males. At T2, Experiential EI was negatively correlated within time with loneliness for males only. We also found across time associations between Experiential EI and Strategic EI for males and females, with higher scores at $\mathrm{T} 1$ predicting higher scores on the other at $\mathrm{T} 2$. We also found that age was correlated with EI, but not loneliness. Table 1 also shows the differences between male and female adolescents for the study variables as measured with Cohen's d: there were small differences between males and females on the study variables. Differences in associations between AEI and loneliness across and within time for males and females suggested we should use multiple-group panel design so we could examine differences in the magnitude and direction of effects for male and female adolescents.

\section{Cross-Lagged Path Analyses}

Cross-lagged path analyses with observed variables were performed in AMOS 21 to examine reciprocal and unidirectional influences between loneliness and the two areas of EI (Experiential EI and Strategic EI) across the two time points observed in this study. All within-time associations and stability coefficients were controlled for (Asendorpf \& Van Aken, 2003) in both the baseline and cross-lagged models. We controlled for the effects of 
age in all analyses. We used multiple-groups analyses that enabled an examination of the model for males and females.

The baseline model included all within-time associations and autoregressive paths. This baseline model had a poor fit to the data $\left(\chi^{2}=105.81, d f=14, p<.001\right.$; CFI $\left.=.85, \mathrm{NFI}=.84, \mathrm{RMSEA}=.13\left[\mathrm{CI}_{95}=.11, .16\right]\right) . \mathrm{Next}$, we included all reciprocal cross-lagged paths, which resulted in a much better fit to the data $\left(\chi^{2}=7.01, d f=2, p=\right.$ $\left..030 ; \mathrm{CFI}=.99, \mathrm{NFI}=.99, \mathrm{RMSEA}=.08\left[\mathrm{CI}_{95}=.02, .13\right]\right)$. A significant difference was found between the baseline and cross-lagged models $\left(\Delta \chi^{2}=98.8, \Delta d f=12, p<\right.$ $.001)$, suggesting that the cross-lagged paths improved the model. The final model for females and males are shown in Figures $1 \mathrm{a}$ and $1 \mathrm{~b}$ respectively. The figures show (1) high levels of stability of the three constructs, (2) reciprocal across time effects for Strategic and Experiential EI, (3) higher Strategic EI predicts reductions in loneliness for male and female participants, (4) higher levels of loneliness predict reductions in Strategic EI for male and female participants, and (5) higher Experiential EI predicts reductions in loneliness only for males.

Results from the Fisher's $r$ to $Z$ transformation statistic showed that there was a difference in the stability coefficients for males and females on loneliness, Experiential EI, and Strategic EI $(Z=3.61,1.97,3.37, p<.001, .001$, and .048 respectively), with females showing higher levels of stability on all three constructs over the 10 month period. There were no differences in the magnitude of the effects of Strategic EI T1 on loneliness T2 $(\mathrm{Z}=1.01, p=.31)$ or loneliness T1 on Strategic EI T2 $(\mathrm{Z}=.34, p=.73)$. Results showed no gender differences in coefficients for Experiential EI T1 to Strategic EI T2 $(Z=1.68, p=.093)$. There was a significant difference between males and females for the coefficient linking Strategic EI T1 to Experiential EI T2 $(Z=3.03, p=$ 
.002 ), with the prospective association being stronger for males.

\section{Discussion}

The aim of the research was to investigate the prospective relationship between loneliness and emotional functioning for a sample of young adolescents when all within-time associations, stability coefficients, and age were controlled. We also looked at the influence of gender on these prospective relationships. For females and males in the current study, we found significant prospective relationships between Strategic EI at T1 and loneliness at T2, and loneliness at T1 and Strategic EI at T2. These findings support the idea that better skills at understanding and managing emotions predict reductions in loneliness over time (Cacioppo \& Hawkley, 2009), but the findings also support the notion that loneliness affects a persons' abilities to understand and manage emotions over time (Cacioppo \& Hawkley, 2009). For males, poorer Experiential EI at T1 was prospectively associated with higher loneliness at T2, suggesting that males who are not able to correctly perceive and use emotions are at risk of increasing loneliness over time.

\section{Emotional Skills Predict Changes in Loneliness}

We found that females with lower Strategic EI and males with lower Strategic and Experimental EI at T1 showed increases in loneliness over the 10 months of the study, which covered the first school year at high school. These findings support the model proposed by Cacioppo and Hawkley (2009) that posits poor emotional skills increase loneliness over time. The findings show that emotional skills matter for loneliness and that they may offer protection against loneliness (Hawkley \& Cacioppo, 2010; Hawkley, Thisted, \& Cacioppo, 2009). Future research could determine exactly how certain emotional skills predict changes in loneliness, and why experiential EI (perceiving and facilitate) might impact loneliness for males and not females. Because of small sample size, we were unable to look at the 
individual dimensions of AEI so we could not examine whether the effects found in the current study for Strategic EI are driven simply by emotion management skill or whether emotion understanding uniquely predicted changes in loneliness over time. Given that emotion understanding involves consideration of the complicated relationship between emotions, including how they change over time, future empirical work should examine whether people who are able to link aversive feelings that arise from loneliness to that event, show decreases in loneliness over time.

\section{Loneliness Decreases Emotional Functioning}

We found that poor emotional functioning skills predicted increases in loneliness, but we also found that loneliness predicted reductions in Strategic EI for both males and females. These findings also fit well with Cacioppo and Hawkley's (2009) theory of loneliness, which proposes that feelings of loneliness impair the capacity to regulate emotions. The proposal is that this particular impairment emerges because loneliness makes people more vigilant to possible social threats in the social environment and that takes attention away from other tasks, including self-regulation. The current study is the first to establish the prospective relationship between loneliness and later emotion regulation, and it does so for young adolescents. Future research may want to examine the mechanism(s) by which loneliness leads to decreases in emotion regulation, and it should investigate possible mechanisms across development.

\section{Gender as a Moderator of the Association between Emotional Skills and Loneliness}

In the current study we found slight differences in the pattern of associations for males and females: there are reciprocal prospective links between Strategic EI and loneliness for males and females, but also prospective associations between Experiential EI and loneliness for males only. It is of interest why there are such differences. The findings might 
be explained by maturity: females tend to score higher on the MSCEIT-YV in early adolescence (Rivers et al., 2012), which reflects their earlier use of emotional information to understand social contexts. Low levels of Experiential EI might be more important in predicting loneliness over time for male and not female youth because male adolescents are still learning to label their emotions effectively. Those males who are able to label correctly the aversive feelings that accompany loneliness are at an advantage compared to their male peers when they come to manage those emotions.

\section{Additional Findings}

Prospective associations between experiential and strategic EI. The prospective associations between Experiential and Strategic EI are also of interest to researchers in the field of EI. We found that that Strategic EI predicted changes in Experiential EI and vice versa, suggesting that being able to label emotions increases one's ability to understand and manage those emotions effectively, but also that being able to regulate emotions impacts one's ability to label emotions correctly. These effects were found for males and females, but, for males, increases in Strategic EI skills were more likely to lead to increases in Experiential EI than was the case for females. It seems, then, that male adolescents may be learning about emotions more through regulating them than females are at this stage in development. Future research should further explore these relationships over time to establish why such gender differences exist. We must also remember that AEI measures whether people have certain emotion knowledge; AEI does not provide us with information about whether a person feels confident enough to use these skills in social contexts (Qualter et al., 2014). Thus, future research may want to examine the prospective associations of different aspects of AEI, Emotional Self-Efficacy, and loneliness. 
Gender differences in temporal stability. Our data also showed that, for our sample, the stability of loneliness, Experiential EI, and Strategic EI was stronger for females than males. These findings regarding stability of loneliness might be sample specific because other prospective studies have not found this effect (e.g., Harris et al., 2013; Jobe-Shields et al., 2011; Qualter, Brown et al., 2013; Vanhalst, Goossens et al., 2013). More prospective research is needed to look at the roles of gender and age in understanding the stability and increase in loneliness over time.

To our knowledge, the stability of Experiential and Strategic EI has not been investigated in an adolescent sample, and our findings suggest that these constructs may be more stable over time for females compared to males. These findings may suggest that environmental and personal factors we have not included in the current study (e.g., parenting and personality traits) affect males and females differently. Future research may want to explore these factors with regard to the relationship between emotional skills and loneliness.

\section{Limitations of the Current Study}

There are some limitations of the current study that future work should attempt to overcome. The first limitation relates to the use of a relatively small sample, which meant we could examine only the two Area scores and not individual dimensions of AEI. In that way, no conclusion can be drawn with regard to specific emotional abilities and their relation to loneliness. Further, our sample is unlikely to be representative of the UK adolescent population because the study was only conducted in one school in England. Finally, we did not control for any background variables, which are known to be associated with loneliness (e.g., depressive symptoms, personality traits, and self-worth) and are likely to impact emotional skills use in social contexts.

\section{Conclusions}


In the current study loneliness and emotional functioning were prospectively associated, supporting the theory that poor emotional skills increase loneliness, but also that loneliness impairs emotion regulation. There were some gender differences that should be further explored in future research. We propose that more research is needed to also examine these prospective associations across more time points and different ages, including adulthood.

\section{References}

Arbuckle, J. L. (2012). IBM SPSS Amos 21. User's Guide. Armonk, NY: IBM.

Asendorpf, J. B., \& van Aken, M. A. G. (2003). Personality-relationship transaction in adolescence: Core versus surface personality characteristics. Journal of Personality, 71, 629-666. doi: 10.1111/1467-6494.7104005

Bangee, M., Harris, R. A., Bridges, N., Rotenberg, K. J., \& Qualter, P. (2014). Loneliness and attention to social threat in young adults: Findings from an eye tracker study. Personality and Individual Differences, 63, 16-23. doi: 10.1016/j.paid.2014.01.039

Brackett, M. A., \& Mayer, J. D. (2003). Convergent, discriminant, and incremental validity of competing measures of emotional intelligence. Personality and Social Psychology Bulletin, 29(9), 1147-58. doi: 10.1177/0146167203254596

Brackett, M. A., Mayer, J. D., \&Warner, R. M. (2004). Emotional intelligence and its relation to everyday behaviour. Personality and Individual Differences, 36(6), 1387402. doi: 10.1016/S0191-8869(03)00236-8

Brackett, M. A., Rivers, S. E., Shiffman, S., Lerner, N., \& Salovey, P. (2006). Relating emotional abilities to social functioning: A comparison of self-report and performance measures of emotional intelligence. Journal of Personality and Social Psychology, 91(4), 780-95. doi: 10.1037/0022-3514.91.4.780 
Brackett, M. A., Warner, R. M., \& Bosco, J. S. (2005). Emotional intelligence and relationship quality among couples. Personal Relationships, 12(2), 197-212. doi: 10.1111/j.1350-4126.2005.00111.x

Cacioppo, J. T., Ernst, J. M., Burleson, M. H., McClintock, M. K., Malarkey, W. B., Hawkley, L. C., . . \& \& Berntson, G. G. (2000). Lonely traits and concomitant physiological processes: The MacArthur social neuroscience studies. International Journal of Psychophysiology, 35(2), 143-154. doi: 10.1016/S0167-8760(99)00049-5

Cacioppo, J. T., \& Hawkley, L. C. (2005). People thinking about people: The vicious cycle of being a social outcast in one's own mind. In K. D. Williams, J. P. Forgas, \& W. von Hippel (Eds.), The social outcast: Ostracism, social exclusion, rejection, and bullying (pp. 91-108). New York, NY: Psychology Press.

Cacioppo, J. T., \& Hawkley, L. C. (2009). Perceived social isolation and cognition. Trends in Cognitive Sciences, 13(10), 447-454. doi: 10.1016/j.tics.2009.06.005

Cacioppo, J. T., Hawkley, L. C., Ernst, J. M., Burleson, M., Berntson, G. G., Nouriani, B., \& Spiegel, D. (2006). Loneliness within a nomological net: An evolutionary perspective. Journal of research in personality, 40(6), 1054-1085. doi: 10.1016/j.jrp.2005.11.007

Cacioppo, J. T., \& Patrick, W. (2008). Loneliness: Human nature and the need for social connection. London, England: Norton.

Ciarrochi, J. V., Chan, A. Y., \& Caputi, P. (2000). A critical evaluation of the emotional intelligence concept. Personality and Individual Differences, 28, 539-561.

Cohen, J. (1988). Statistical power analysis for the behavioral sciences (second ed.). Hillsdale, NJ: Erlbaum.

de Jong-Gierveld, J. (1987). Developing and testing a model of loneliness. Journal of Personality and Social Psychology, 53, 119-128. doi: 10.1037/0022-3514.53.1.119 
RUNNING HEAD: LONELINESS AND EMOTIONAL INTELLIGENCE

Harris, R. A., Qualter, P., \& Robinson, S. J. (2013). Loneliness trajectories from middle childhood to pre-adolescence: Impact on perceived health and sleep disturbance. Journal of Adolescence, 36(6), 1295-1304. doi: 10.1016/j.adolescence.2012.12.009

Hawkley, L. C., \& Cacioppo, J. T. (2010). Loneliness matters: A theoretical and empirical review of consequences and mechanisms. Annals of Behavioral Medicine, 40(2), 218-227. doi: 10.1007/s12160-010-9210-8

Hawkley, L. C., Thisted, R. A., \& Cacioppo, J. T. (2009). Loneliness predicts reduced physical activity: Cross-sectional and longitudinal analyses. Health Psychology, 28(3), 354-363. doi: 10.1037/a0014400

Heinrich, L. M., \& Gullone, E. (2006). The clinical significance of loneliness: A literature review. Clinical Psychology Review, 26, 695-718. doi: 10.1016/j.cpr.2006. 04.002

Jobe-Shields, L., Cohen, R., \& Parra, G. R. (2011). Patterns of change in children's loneliness: Trajectories from third through fifth grades. Merrill-Palmer Quarterly, 57(1), 25-47. doi: 10.1353/mpq.2011.0003

Ladd, G., \& Ettekal, I. (2013). Peer-related loneliness across early to late adolescence: Normative trends, intra-individual trajectories, and links with depressive symptoms. Journal of Adolescence, 36(6), 1269-1282. doi: 10.1016/j.adolescence.2013.05.004

Leadbeater, B. J., Kuperminc, G. P., Blatt, S. J., \& Hertzog, C. (1999). A multivariate model of gender differences in adolescents' internalizing and externalizing problems. Developmental Psychology, 35(5), 1268-1282.

Little, R. J. A., \& Rubin, D. B. (1987). Statistical analysis with missing data. New York, NY: Wiley. 
Lopes, P. N., Brackett, M. A., Nezlek, J. B., Schütz, A., Sellin, I., \& Salovey, P. (2004). Emotional intelligence and social interaction. Personality and Social Psychology Bulletin, 30, 1018-1034. doi: 10.1177/0146167204264762

Lopes, P. N., Salovey, P., \& Straus, R. (2003). Emotional intelligence, personality, and the perceived satisfaction of social relationships. Personality and Individual Differences, 35, 641-658. doi: 10.1016/S0191-8869(02)00242-8

Marcoen, A., Goossens, L., \& Caes, P. (1987). Loneliness in pre- through late adolescence: Exploring the contributions of a multidimensional approach. Journal of Youth and Adolescence, 16(6), 561-577. doi: 10.1007/BF02138821

Marsh, H. W., Hau, K. T., \& Wen, Z. L. (2004) In search of golden rules: Comment on hypothesis testing approaches to setting cutoff values for fit indexes and dangers in overgeneralizing Hu \& Bentler (1999) findings. Structural Equation Modeling, 11, 320-341. doi: 10.1207/s15328007sem1103_2

Márquez, P. G., Martín, R. P., \& Brackett, M. A. (2006). Relating emotional intelligence to social competence and academic achievement in high school students. Psichothema, 18, 118-123.

Mayer, J. D., Salovey, P., \& Caruso, D. R. (2002). Mayer-Salovey-Caruso Emotional Intelligence Test (MSCEIT) user's manual. Toronto, Canada: Multi Health Systems .

Mayer, J. D., Salovey, P., \& Caruso, D. R. (2005). The Mayer-Salovey-Caruso Emotional Intellingence Test - Youth Version (MSCEIT-YV). Research version. Toronto, Canada: Multi Health Systems.

Mayer, J. D., Salovey, P., \& Caruso, D. R. (2008). Emotional intelligence: New ability or eclectic traits? American Psychologist, 63(6), 503-517. doi: 10.1037/0003066X.63.6.503 
Mestre, J. M., Guil, R., Lopes, P. N., Salovey, P., \& Gil-Olarte, P. (2006). Emotional intelligence and social academic adaptation to school. Psicothema, 18, 112-117.

Nightingale, S., Roberts, S., Tariq, V., Appleby, Y., Barnes, L., Harris, R.A., Dacre-Pool, L. \& Qualter, P. (2013). Trajectories of university adjustment in the United Kingdom: Emotion management and emotional self-efficacy protect against initial poor adjustment. Learning and Individual Differences, 27, 174-181. doi: 10.1016/j.lindif.2013.08.004

Pellegrini, A. D. (2002). Bullying, victimization, and sexual harassment during the transition to middle school. Educational Psychologist, 37(3), 151-163. doi: 10.1207/S15326985 EP3703_2

Pellegrini, A. D., \& Long, J. D. (2002). A longitudinal study of bullying, dominance, and victimization during the transition from primary school through secondary school. British Journal of Developmental Psychology, 20, 259-280. doi: 10.1348/026151002166442

Peplau, L. A., \& Perlman, D. (1979). Blueprint for a social psychological theory of loneliness. In M. Cook \& G. Wilson (Eds.), Love and attraction (pp. 99-108). Oxford, England: Pergamon.

Perlman, D., \& Peplau, L. A. (1981). Toward a social psychology of loneliness. In R. Duck \& R. Gilmour (Eds.), Personal relationships in disorder (pp. 31-56). London, England: Academic Press.

Qualter, P., Brown, S. L., Munn, P., \& Rotenberg, K. J. (2010). Childhood loneliness as a predictor of adolescent depressive symptoms: An 8-year longitudinal study. European Child and Adolescent Psychiatry, 19, 493-501. doi: 10.1007/s00787-0090059-y

Qualter, P., Brown, S. L., Rotenberg, K. J., Vanhalst, J., Harris, R. A., Goossens, L., . . \& Munn, P. (2013). Trajectories of loneliness during childhood and adolescence: 
Predictors and health outcomes. Journal of Adolescence, 36, 1283-1293. doi: 10.1016/j.adolescence.2013.01.005

Qualter, P., Dacre-Pool, L., Gardner, K. J., Ashley-Kot, S., Wise, A., \& Wols, A. (2014). The emotional self-efficacy scale: Adaptation and validation for young adolescents. Journal of Psychoeducational Assessment. Published online before print. doi: 10.1177/0734282914550383

Qualter, P., Rotenberg, K., Barrett, L., Henzi, P., Barlow, A., Stylianou, M., \& Harris, R. A. (2013). Investigating hypervigilance for social threat of lonely children. Journal of Abnormal Child Psychology, 41(2), 325-338. doi: 10.1007/s10802-012-9676-x

Rivers, S. E., Brackett, M. A., Reyes, M. R., Mayer, J. D., Caruso, D. R., \& Salovey, P. (2012). Measuring emotional intelligence in early adolescent with the MSCEIT-YV: Psychometric properties and relationship with academic performance and psychosocial functioning. Journal of Psychoeducational Assessment, 30(4), 344-366. doi: $10.1177 / 0734282912449443$

Rivers, S. E., Brackett, M. A., \& Salovey, P. (2008). Measuring emotional intelligence as a mental ability in adults and children. In G. J. Boyle, G. Matthews \& D. H. Saklofske (Eds.), The SAGE handbook of personality theory and assessment. Vol. 2: Personality measurement and testing (pp.440-460). London, England: SAGE.

Schinka, K. C., van Dulmen, M. H., Bossarte, R., \& Swahn, M. (2012). Association between loneliness and suicidality during middle childhood and adolescence: Longitudinal effects and the role of demographic characteristics. The Journal of Psychology, 146(1-2), 105-118.

Schinka, K. C., van Dulmen, M. H., Mata, A. D., Bossarte, R., \& Swahn, M. (2013). Psychosocial predictors and outcomes of loneliness trajectories from childhood to 
RUNNING HEAD: LONELINESS AND EMOTIONAL INTELLIGENCE

early adolescence. Journal of Adolescence, 36, 1251-1260. doi: 10.1016/j. adolescence. 2013.08 .002

Stough, C., Saklofske, D. H., \& Parker, J. D. A. (2009). Assessing emotional intelligence: Theory, research, and applications. New York, NY: Springer.

Vanhalst, J., Goossens, L., Luycks, K., Scholte, R. H., \& Engels, R. C. (2013). The development of loneliness from mid-to late adolescence: Trajectory classes, personality traits, and psychosocial functioning. Journal of Adolescence, 36(6), 1305-1312. doi: 10.1016/j.adolescence.2012.04.002

Vanhalst, J., Klimstra, T. A., Luyckx, K., Scholte, R. H. J., Engels, R. C. M. E., \& Goossens, L. (2012). The interplay of loneliness and depressive symptoms across adolescence: Exploring the role of personality traits. Journal of Youth and Adolescence, 41(6), 776-787. doi: 10.1007/s10964-011-9726-7.

Vanhalst, J., Luyckx, K., Raes, F., \& Goossens, L. (2012). Loneliness and depressive symptoms: The mediating and moderating role of uncontrollable ruminative thoughts. The Journal of Psychology: Interdisciplinary and Applied, 146(1-2), 259-276. doi: 10.1080/ 00223980.2011 .555433

Vanhalst, J., Rassart, J., Luyckx, K., Goossens, E., Apers, S., Goossens, L., \& Moons, P. (2013). Trajectories of loneliness in adolescents with congenital heart disease: Associations with depressive symptoms and perceived health. Journal of Adolescent Health, 53(3), 342-349. doi: 10.1016/j.jadohealth.2013.03.027

Wigfield, A., Eccles, J. S., MacIver, D., Reuman, D. A., \& Midgley, C. (1991). Transitions during early adolescence: Changes in children's domain-specific self-perceptions and general self-esteem across the transition to junior high school. Developmental Psychology, 27(4), 552-565. doi: 10.1037/0012-1649.27.4.552 
RUNNING HEAD: LONELINESS AND EMOTIONAL INTELLIGENCE

Young, J. E. (1982). Loneliness, depression, and cognitive therapy: Theory and application. In L. A. Peplau, \& D. Perlman (Eds.), Loneliness: A sourcebook of current theory, research and therapy (pp. 379-405). New York, NY: Wiley.

Zysberg, L. (2012). Loneliness and emotional intelligence. The Journal of Psychology, 146(1-2), 37-42. doi: 10.1080/00223980.2011.574746 